\title{
Why Buy Accident Forgiveness Policies? An Experiment
}

\author{
Fan Liu $^{1}$ \\ ${ }^{1}$ John L. Grove College of Business, Shippensburg University, Pennsylvania, USA \\ Correspondence: Fan Liu, John L. Grove College of Business, Shippensburg University, Pennsylvania 17257, \\ USA. Tel: 717-477-1786. E-mail: fliu@ ship.edu
}

Received: March 28, 2018

Accepted: May 7, 2018

Online Published: June 28, 2018

doi:10.5539/ijef.v10n8p1

URL: https://doi.org/10.5539/ijef.v10n8p1

\begin{abstract}
Risk and time preferences influence the insurance purchase decisions under uncertainty. Accident forgiveness, often considered as "premium insurance," protects policyholders against a premium increase in the next period if an at-fault accident occurs. In this paper, by conducting a unique experiment in the controlled laboratory conditions, we examine the role of risk and time preferences in accident forgiveness purchase decisions. We find that individual discount rates and product price significantly affect premium insurance purchase decision. Interestingly, we also find evidence that less risk averse policyholders in general behave more like risk neutral when making insurance decision. Risk attitudes affect insurance decision-making only among those who have relatively high degree of risk aversion.
\end{abstract}

Keywords: accident forgiveness, experiment, insurance economics, joint estimation, time and risk preferences

\section{Introduction}

Risk and time preferences influence a variety of economic behaviors, such as investment and portfolio choice. In the field of insurance economics, attitudes toward risk and time play central roles in insurance decision-making.

An auto insurance accident forgiveness policy, also known as a "premium insurance" policy, protects policyholders against a premium increase in the next period if an at-fault accident occurs in the previous period. While accident forgiveness policies are popular, the driving forces behind individual purchases are unclear.

A premium "locked-in" low rate guarantee as one of the features of an accident forgiveness policy invokes the importance of time preferences in the purchase. Policyholders who prefer to secure their future insurance premiums or, in other words, smooth their utility over future periods are believed to have different purchase preferences over this policy compared to those who are more concerned about current consumption relative to the future. Moreover, as stated by Harrison and Rutström (2008), attitude toward risk is one of the primitives of economies and characterizations of the distribution of risk attitudes can be used to analyze the choice behavior under uncertainty. Prior research (e.g., Laury \& McInnes, 2003; Kunreuther \& Pauly, 2005) predicts that risk-averse individuals always demand more insurance. However, this may not apply to the purchase of accident forgiveness. An experiment conducted in this paper shows that some good drivers (drivers with a low probability of having accidents) are not interested in purchasing this optional policy to protect their potential loss, even when the insurance price is actuarially fair. For both the insurer and the insured, the question of how risk and time preferences affect individual accident forgiveness purchases is critical to understanding such policy design.

In this paper, we address this question by conducting an experiment under controlled laboratory conditions. The experiment consists of the following tasks: a lottery choice task, a discount rate task, a simulated driving task, and an insurance purchase task. The random lottery pair design is used in the lottery choice task to infer risk attitudes. We combine the lottery choice task with the discount rate task to jointly infer discount rates over utility since it is the concavity of the utility function that is important, and under expected utility theory (EUT) this is synonymous with risk attitude. The simulated driving task is used to assess subjects'driving behavior. By offering insurance contracts conditional on observed driving behavior in the insurance purchase task, we can construct a close representation of a naturally-occurring auto insurance market in which insurance premiums are based upon driver risk classifications.

The statistical specification in this paper involves the joint estimation of risk attitudes, time preferences, and insurance decisions. We consider models that allow for both observable individual characteristics and structural errors and assume both exponential and hyperbolic (Mazur) specifications of the discount rate function. The 
estimates show moderate risk aversion $(\gamma=0.36)$ and a discount rate of 1.28 (or 0.88 , assuming hyperbolic discounting), on average. To test the hypotheses of the impact of risk and time preferences on accident forgiveness purchases, we examine the data obtained from the experiment and find that individual discount rates and policy prices have significantly negative effects on accident forgiveness purchases. More importantly, inconsistent with the prior literature, which argues the positive impacts of risk aversion on insurance purchases, our data show that subjects with a lower degree of risk aversion behave more like risk-neutral agents when making insurance decisions. In other words, their degree of risk aversion does not contribute to their insurance purchases. However, those with a higher degree of risk aversion make insurance decisions that are significantly driven by their risk attitudes.

Our study is unique in several ways: First, prior studies focus on explaining the determinants of individual insurance purchases for the severe consequences arising from low-probability high-loss events (e.g., earthquakes and floods). This paper contributes to the existing literature by addressing the impact of risk and time preferences on insurance decision- making over events with moderately high probability but relatively low loss (e.g., premium increases after auto accident) (Note 1). By centering the analysis on accident forgiveness purchases, this study improves our understanding of this new policy as well as reveals important implications for insurance policy makers.

Second, only a few studies address the joint elicitation of risk and time preferences. Andersen et al. (2008) was the first to focus on the formal theoretical link between elicited risk attitudes and individual discount rates. We extend the existing literature by using full information maximum likelihood in the joint elicitation of risk and time preferences. More specifically, we further elicit risk and time preferences jointly with insurance decisions. Moreover, instead of using a probit model over the entire sample to investigate the impact of risk preferences on accident forgiveness purchases, we adopt a conditional probit model in which the level of risk aversion is controlled. Three subsamples are drawn by the centile of risk aversion (e.g., below the 25th percentile, between the 25th and 75th percentiles, and above the 75th percentile). The result shows that the impacts of risk aversion on accident forgiveness purchases vary among these subsamples. The significantly positive effect is only observable in the subsample with a higher level of risk aversion and this interesting finding is consistent with the threshold explanation developed in Liu (2015).

Third, prior experimental literature studying insurance purchase decisions rarely classifies a subject's risk type. However, in practice, this is important. For most lines of insurance products (e.g., homeowner insurance and auto insurance), insurers provide insurance contracts to policyholders conditional on their risk types. Different risk types of policyholders may follow different decision rules when purchasing insurance. By offering subjects an insurance contract conditional on their driving behavior observed in the simulated driving task, the design of this experiment enables us to infuse the experiment with realism.

Section 2 reviews both the insurance and the experimental literature on insurance decision- making. Section 3 proposes testable hypotheses. Section 4 presents the experimental design, which allows the joint estimation of risk and time preferences with insurance purchase decisions. Section 5 outlines the estimation procedure. Section 6 examines the data from the experiment and econometric analysis. Section 7 summarizes what may be improved in the experimental design and Section 8 draws some general conclusions.

\section{Literature Review}

Consumers often face decisions as to whether to purchase insurance. There is a vast literature on insurance purchase decision-making. Anderson (1974) evaluates the National Flood Insurance Program and concludes that consumer awareness of a product's existence and the level premium rates determine insurance purchases. Kunreuther et al. (2001) and Kunreuther and Pauly (2004) formulate the idea of decision-making costs and imperfect information in ways that help explain "anomalies" in insurance markets. The authors find that individuals may face an explicit or implicit cost to discovering the true probability of rare events and this cost constitutes a threshold that might inhibit purchase. Further, Kunreuther and Pauly (2006) propose more details about why consumer insurance-purchasing activities do not always produce results in the best interest of the individuals at risk. The authors reveal that individuals for whom insurance may be a financially attractive investment may be reluctant or unable to collect the information they need to make decisions due to the time, effort, and costs associated with the process. In addition, individuals may exhibit "misprocessing behavior," including a misperception of the risks, with simplified decision rules and reluctance to consider new alternatives. Krantz and Kunreuther (2007) pursue a more Aristotelian theory of decision making, where preferences are constructed based on the decision context and decision makers focus on goals, rather than on maximizing happiness or utility. The authors attempt to show that this alternative approach leads to new explanations of how 
people make insurance decisions.

Controlled laboratory experiments are an ideal testbed for insurance purchase decision analysis (Laury et al., 2009). The most widely cited laboratory study of insurance purchase decisions was conducted by Slovic et al. (1977). This involves a carefully-crafted experiment in which subjects fill out a questionnaire that elicits their willingness to purchase actuarially fair insurance in up to eight different situations. The probabilities and sizes of the losses are systematically varied across questions, holding constant the expected value of the loss and the actuarially fair premium. The authors find that the percentage of subjects purchasing insurance is relatively low when the probability of loss is very low (and therefore the loss amount is high) and systematically increases with the probability of loss. McClelland et al. (1993) conduct an experimental study of insurance purchase decisions in which groups of eight subjects participate in a Vickrey fifth-price auction and they find that these laboratory results are consistent with field evidence for low-probability hazards, for which people appear to either dismiss the risks or worry too much about them. Ganderton et al. (2000) present a series of experiments that confronted subjects with also focusing on low-probability, high- loss situations. The authors illustrate that as loss events become more likely, loss amounts increase, or the cost of insurance falls, subjects are more likely to buy indemnifying insurance, even for the class of low probability risks that usually present problems in standard EUT. Laury and McInnes (2003) conduct an experiment that tests whether showing subjects actuarially fair insurance prices reduces deviations from optimal (Bayesian) decision making. The authors find significant differences in the decision rules used, depending on whether one observes insurance prices. Further, Laury et al. (2009) undertake a systematic study to reexamine the issue of whether individuals tend to underinsure against low-probability, high-loss events relative to high-probability, low-loss events. Their results counter prior experimental evidence, since they observe subjects buying more insurance for lower-probability events than for higher-probability events, given a constant expected loss and load factor, and the authors conclude that this may be attributed to factors other than the relative probabilities of the loss events.

Insurance behavior in the laboratory is very sensitive to how the losses are framed and the types of incentives used. When insurance decisions are presented in abstract terms, with no money on the line, subjects were indeed less likely to insure against smaller probability losses (Laury et al., 2009). This study focuses on insurance decision-making over events with moderately high probability but relatively small loss and builds on prior literature on the design of the experiment by framing insurance decisions in a less abstract context. More specifically, subjects in the experiment face the potential loss of part or all of their earned amount from other tasks and are asked to make decisions whether to purchase insurance. Further, by assessing subject's driving behavior from the simulated driving task and offering insurance contracts conditional on the observed driving behavior, our experimental design reflects decision-making patterns in naturally occurring auto insurance markets.

\section{Hypotheses}

The goal is to develop an experiment to study the impacts of risk and time preferences on accident forgiveness purchases. Before we present our experimental design, we wish to describe two testable hypotheses concerning the effects of individual discount rates and the degree of risk aversion and how they relate to the decision to purchase accident forgiveness coverage.

\subsection{Individual Discount Rates}

Time preference is a provocative subject with important implications for many aspects of economic behavior and public policy (Warner \& Pleeter, 2001). It is particularly essential in insurance decision-making. The macroeconomic literature provides evidence of the relation between the discount factor and life insurance purchases in a life cycle model (e.g., Fischer, 1973; Yaari, 1965) (Note 2). Articles related to dynamic insurance contracts further demonstrate the importance of time preferences. Rubinstein and Yaari (1983) show that multi-period insurance contracts can increase the welfare of both the insurer and the insured when the number of periods is large and the discount rate is small. Dionne and Doherty (1994) find a positive relation between the discount factor and high-risk driver participation in the first-period pooling insurance. Kunreuther (1996) uses time preferences to explain why individuals have limited interest in voluntary insurance purchases.

As premium insurance, an important characteristic of accident forgiveness is that future premiums will be locked in (e.g., there will be no surcharges on premiums after any at-fault accidents) if this optional policy is purchased. We argue that more patient policyholders prefer to smooth their utility rather than have distinct differences over time. In other words, they care more about their future premiums. To secure future premiums, they are more likely to purchase optional accident forgiveness policies to increase the possibility of future insurance. This suggests that policyholders with lower discount rates are more likely to have a higher demand for accident 
forgiveness.

\subsection{Degree of Risk Aversion}

The impact of individual risk attitudes on insurance purchase decisions is the subject of some debate in the literature. Schlesinger and Schulenberg (1987) argue that because a higher degree of risk aversion implies a greater relative emphasis on downside risk, an increase in the level of risk aversion leads to the purchase of a higher level of insurance coverage. Ganderton et al. (2000) state that all risk-neutral or risk-averse individuals would purchase insurance and undertake all relevant precautions to the extent that the extra benefits from such actions exceed the marginal costs, less some risk premium in the case of risk aversion. Laury and McInnes (2003) point out that all risk-averse people should purchase insurance, regardless of whether one group is significantly more risk averse than the other. Kunreuther and Pauly (2005) argue that as long as people are risk averse, people will be willing to pay a premium greater than or equal to the expected value of losses from a set of uncertain events against which they will be covered. The maximum amount that an individual will be willing to pay for coverage depends on her degree of risk aversion. However, the threshold explanation (McClelland et al., 1993) predicts that risk-averse individuals will not buy insurance unless they view the hazard as a problem worthy of concern. This threshold concept makes good intuitive sense, since the authors point out that without some sort of threshold for concern, people would spend their entire lives excessively protecting themselves against loss events.

As observed in the experiment, risk-averse drivers (e.g., drivers with good driving behavior) do not always purchase optional insurance. Even with an actuarially fair premium, some still hesitate to purchase it. In line with the threshold explanation derived in Liu (2015), we argue that more risk-averse policyholders will be more likely to purchase accident forgiveness if their degree of risk aversion is above a given threshold. The basic intuition is as follows. An individual's risk attitude determines the curvature of the utility function. For policyholders with a relatively higher degree of risk aversion, the price for accident forgiveness may be acceptable in terms of what they feel they are getting for the money. Then the more risk-averse policyholders become, the more likely they will purchase accident forgiveness. Meanwhile, policyholders with a lower degree of risk aversion behave more like risk-neutral individuals. While risk averse, their degree of risk aversion does not affect their insurance purchases. Other factors such as personal experience and the affordability of insurance prices are more likely to contribute to their decisions.

\section{Experimental Procedures}

A total of 60 subjects were recruited from across the university campus to participate in the experiment. Their ages ranged from 18 to 57 (mean $=22.5 \pm 5.9)$ and 39 of subjects were female. The general recruitment message did not mention a fee for showing-up or any specific range of possible earnings. Every subject received a copy of the instructions and had time to read them after being seated in the lab.

In brief, each subject was asked to respond to four categories of tasks, including choices over risky prospects, sooner versus later payment choices, simulated driving, and insurance purchases. Most of these tasks involved a series of binary choices. All subjects also completed a demographic survey covering their characteristics, as well as cigarette and alcohol use.

\subsection{Choices over Risky Prospects}

To elicit risk preferences, the experiment used the random lottery pair experimental design of Hey and Orme (1994). A major advantage of this design over the others is that the task is simple and context free. The task involves a modest extension of the display of Harrison and Rutström (2009) in which lotteries are presented to the subjects in color on a computer screen and the information on the probabilities of each pie slice is included. Figure 1 presents an example of such screen-shots, with the subject observed for the task.

A gain frame as well as a mixed frame of lotteries was included. In the gain frame tasks, the prizes in each lottery are nonnegative and in the mixed frame some of the lotteries involve gains and some involve losses. A total of $68 \%$ of the subjects were presented with the gain frame. In all, 40 lottery pairs were drawn at random from a set of 60 lottery pairs. In the gain frame tasks, the prizes in each lottery were $\$ 0, \$ 5.00, \$ 10.00$ and $\$ 15.00$. In the mixed frame tasks subjects were given an initial endowment of $\$ 8.00$ and the prizes were $-\$ 8.00$, $-\$ 3.00, \$ 3.00$ and $\$ 8.00$ (Note 3). Therefore, the final outcomes for the mixed frame, inclusive of the endowment, were $\$ 0, \$ 5.00, \$ 11.00$ and $\$ 16.00$. The probabilities used in each lottery ranged roughly evenly over the unit interval with values of $0,0.13,0.25,0.37,0.5,0.62,0.75$, and 0.87 . These are based on the lottery pairs developed by Harrison and Rutström (2009) and were presented sequentially. Although there was often some similarity in the prizes and probabilities from task to task, the subject did not know the exact lotteries to come, 
which can make the task of forming portfolios very demanding (Hey \& Lee, 2005a, 2005b). Subjects were instructed that one of the pairs from the task would be randomly selected and that they would receive the alternative they chose for that pair in the form of cash at the end of the session. Such random selection is intended to avoid possible wealth effects from paying all choices sequentially during the experiment and portfolio effects from paying all choices at the end of the experiment (Cox et al., 2011).

\subsection{Sooner versus Later Payment Choices}

Eliciting individual discount rates over monetary outcomes in the laboratory involves asking the subject (implicitly or explicitly) to invest in a laboratory instrument. We applied the experimental procedure introduced by Coller and Williams (1999) and expanded by Harrison et al. (2002) in which subjects choose to receive a fixed amount on a given date or a fixed amount plus \$x some days later, where \$x implies a rate of return on "saving" the amount in the lab for some days.

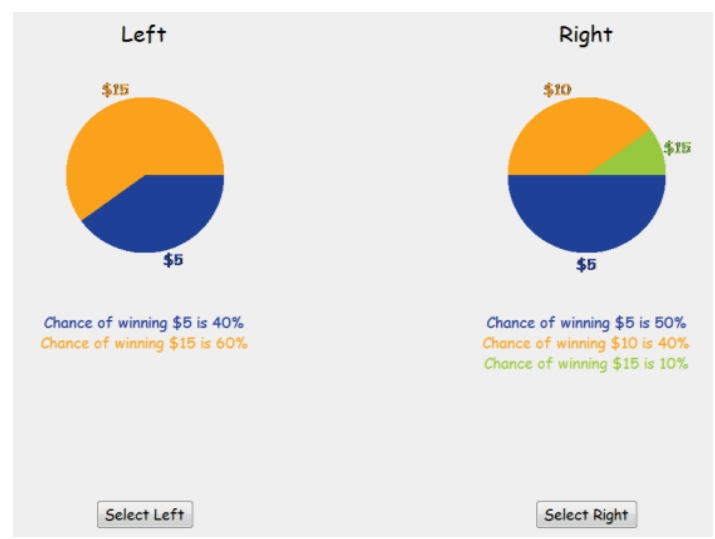

Figure 1. The lottery display for risk preference tasks

This task used principal amounts of $\$ 30.00$ and $\$ 60.00$ and time horizons of seven, $14,21,28,35,42,49,56,63$, and 70 days (one to 10 weeks). Each subject made 40 choices: For each horizon, they were offered four choices, with annual growth rates selected at random between 5\% and 200\%. There was no front-end delay on the earlier option, so the choice was between receiving money now and receiving it later, as illustrated in Figure 2. One decision row was selected at random, to be paid out at the chosen date. All subjects were paid in cash at the end of sessions for any immediate payment choices, as well as by PayPalTMfor any time-delayed payment choices (Note 4). To ensure credibility of the payment instrument, a signed certificate was given as a guarantee of the time-delayed payment (Note 5).

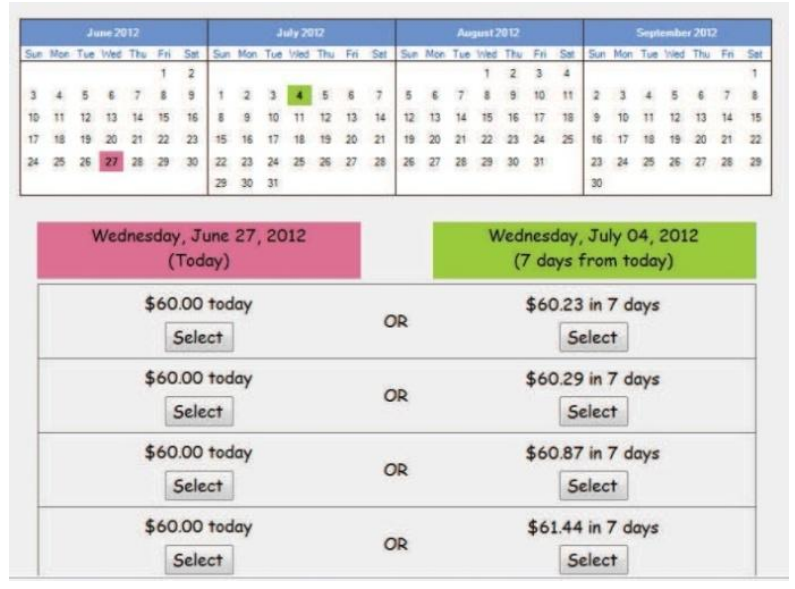

Figure 2. The display for time preferences task

The fraction of choices subjects made by selecting later payments in the discount rate tasks is captured in Figure 3. Using a local polynomial regression with a $95 \%$ confidence interval, even with higher interest rates (e.g., an annual growth rate of 200\%), the fraction of later payment choices (or fraction of "LL choices" in Figure 3) with a principal amount of $\$ 30.00$ is still very low (below 25\%), as illustrated in Figure 3(a). In other words, 
regarding payment choices between receiving $\$ 30.00$ today and $\$ 30.00$ plus $\$ \mathrm{x}$ some days later, most subjects opted to receive immediate payments. The low fraction of later payment choices may be explained by the fact that smaller amounts are discounted more than larger amounts. On the other hand, the fraction of later payment choices with a principal amount of $\$ 60.00$ is much higher, as shown in Figure 3(b), and carries more information that can be used to elicit individual discount rates. Hence, further analysis is focused on choices with $\$ 60.00$ as the principal amount.

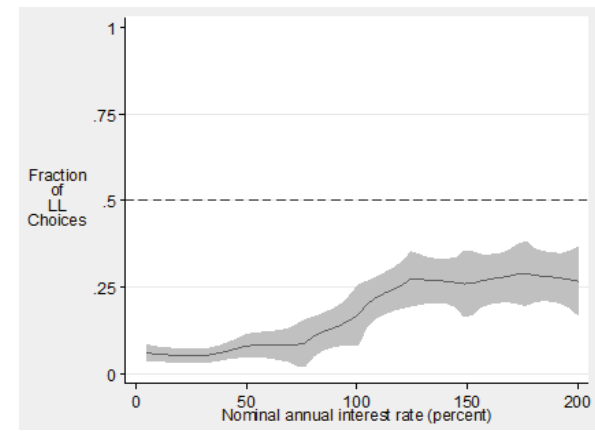

(a) Principal Amount of $\$ 30.00$

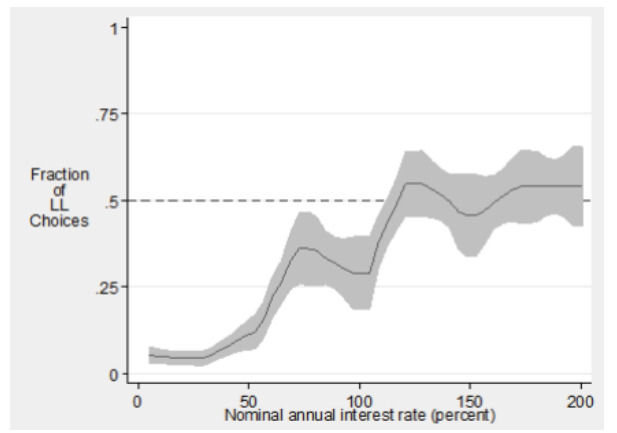

(b) Principal Amount of $\$ 60.00$

Figure 3. Choices of later payment and interest rate offered

\subsection{The Simulated Driving Task}

Understanding the policyholder's driving behavior is essential due to the fact that the pricing of accident forgiveness is conditional on the policyholder's driving skills. To infer a subject's driving behavior in the laboratory environment, this study used a driving simulator. Driving simulators have been used in many contents. For example, Strayer et al. (2003) used simulated driving tasks to examine the effects of hands-free cell phone conversations on traffic safety. Rutström (2011) assessed the risk attitudes of drivers and characteristic biases in how they form beliefs over travel times by using a simulated driving scenario.

The simulator comprised networked microprocessors and one high-resolution display. In addition, a steering wheel, gas pedal, brake pedal, and automatic transmission were part of the simulator equipment. The simulator incorporated proprietary vehicle dynamics, traffic scenarios, and road surface software to provide realistic scenes and traffic conditions. Measures of real-time driving performance, such as travel time, driving speed, brake, gas, and steering wheel inputs, were stored to grade subject's driving skills.

The task consisted of an unpaid practice drive and a paid drive. Subjects were provided with detailed instructions for each drive. By carrying out the unpaid drive, subjects familiarized themselves with the equipment. Different routes were designed for the unpaid and paid drives to reduce any negative learning effects that could bias the estimation.
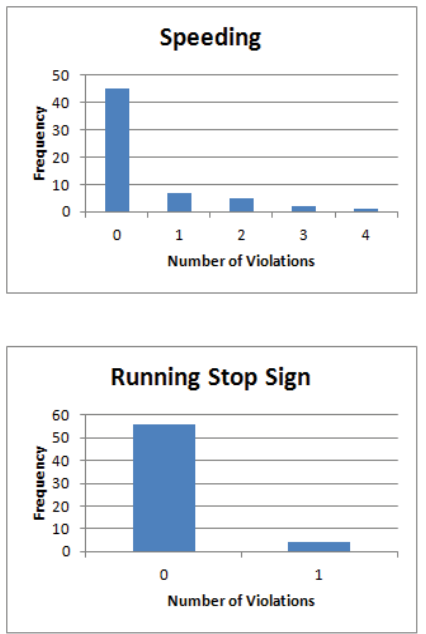

(a) Frequency of Violations
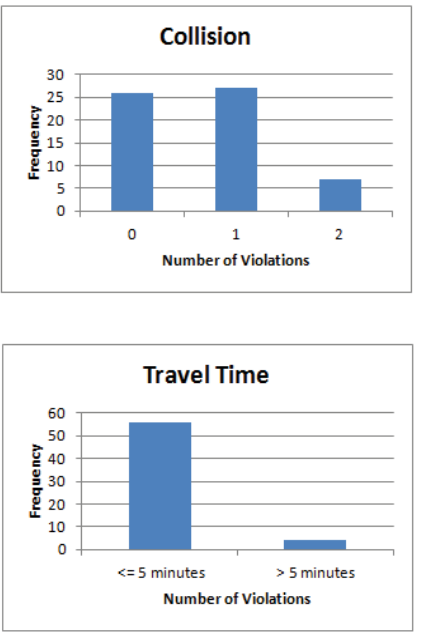

Figure 4. Violations and penalty points

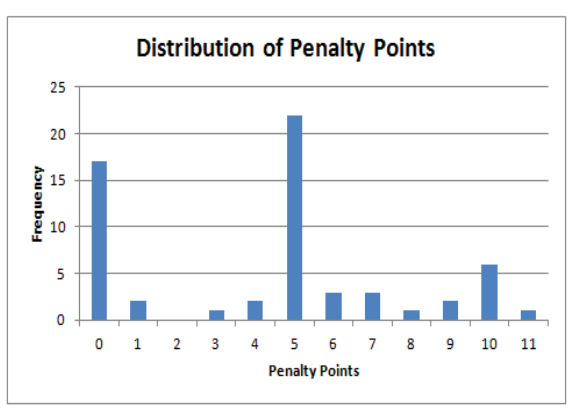

(b) Distribution of Penalty Points 
Earnings for this task were determined by each subject's driving performance. Violations and the relevant penalties were clearly specified in the instructions. Violations included speeding, collision, and running a red light or a stop sign. To control for time effects on driving performance, subjects were also required to finish the driving task within a specific time frame (Note 6). Failure to do so resulted in a reduced payment (Note 7) The earnings for the paid drive were either $\$ 30.00$ or $\$ 60.00$, depending on the total number of penalty points earned (Note 8). Further, earnings from this task would be used as endowments for participating in the next insurance purchase tasks. Figure 4 illustrates the frequency of violations in each category and the distribution of violation points in the sample.

\subsection{The Insurance Purchase Task}

Framing must be carefully dealt with when conducting experiments in the context of insurance. Experimental evidence shows that framing an insurance task as an abstract gamble or as a loss makes a difference to subjects. Hershey and Schoemaker (1980), using hypothetical questions, find that subjects exhibit more risk aversion in choices that are presented in an insurance context than in mathematically equivalent choices presented as standard gambles. Similarly, Laury et al. (2009) state that when insurance decisions are presented in abstract terms, with no money on the line, it is hard to elicit subjects' preferences of insuring against losses and subjects are more likely to buy insurance. To elicit individual preferences over accident forgiveness, insurance decisions were framed in a less abstract context and losses were expressed in dollar terms. Earnings obtained from the driving task were then used as endowments to minimize a found-money effect and to make the loss more real to subjects (Camerer \& Hogarth, 1999; Harrison et al., 2005).

Determined by their driving performance in the previous task, subjects were classified as either high risk or low risk, with high risks being those who earned $\$ 30.00$ from the driving task. Subjects were asked to make an insurance purchase decision for each question in a set of six questions varying in the loss settings, as shown in Figure 5. The subjects faced a potential loss of part or all of this earned amount but potential losses were never larger than a subject's available amount in order to avoid confounding the size of losses with bankruptcy considerations (Note 9). Subjects of the same risk type faced the same set of insurance purchase questions. By offering optional insurance to fully cover potential loss, we imply subjects' preferences for an accident forgiveness policy.

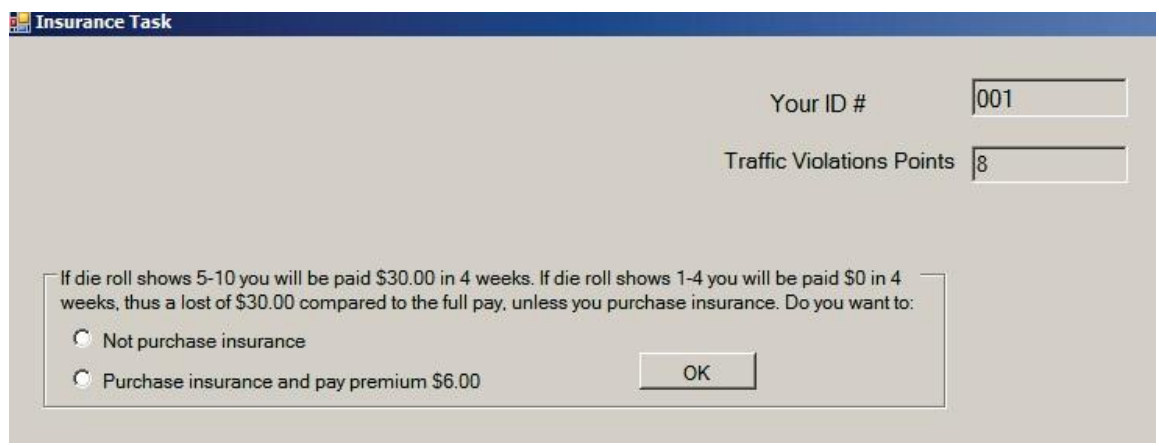

Figure 5. Display for the insurance purchase task

When examining the insurance decision by the experiment, it is not a simple question to ask subjects whether to purchase insurance without adjusting the probability of loss and the insurance load. One feature of the premium loss is its relatively high probability. For example, the probability of the premium loss from auto accidents can be much higher than that caused by a flood or an earthquake. This experiment sets probabilities of a potential loss at $(0.4,0.6)$ for high risks and $(0.1,0.2)$ for low risks while controlling the constant expected value of the loss with $\$ 6.00$ for low risks and $\$ 12.00$ for high risks. In addition, the insurance loads are set to be $0.5,1.0$, and 1.5. When the load is set at 0.5 , the price of insurance is $50 \%$ of the expected value of the loss, indicating subsidization; when the load is 1.0, the insurance is actuarially fair; and when the load is 1.5 , the price of insurance is 1.5 times the expected value of the loss, indicating an overcharge or high loading. Combining the choices for the probability of loss and the insurance load represents a within-subjects factorial design and yields the six decisions for each type. At the end of this task, one decision row is selected at random to be played out.

\section{Econometrics}

To estimate risk attitudes, two broad methods are used. One approach is to calculate the bounds implied by the observed choices, typically using utility functions that have only a single parameter to be inferred (e.g., Holt and 
Laury, 2002). The limitation of this approach is that one must infer the bounds that make the subject indifferent between the switch points, and such inferences become virtually incoherent statistically when there are two or more parameters. The other more preferable approach involves direct estimation by maximum likelihood of some structural model of a latent choice process in which the core parameters defining risk attitudes can be estimated, in the manner pioneered by Camerer and Ho (1994) and Hey and Orme (1994) (Note 10). This is the approach used here and is outlined as follows.

Assume that utility function is defined by

$$
U(\chi)=\frac{(\omega+\chi)^{(1-\gamma)}}{1-\gamma}
$$

where $\mathrm{w}$ is some measure of background consumption (e.g., endowment), $\mathrm{x}$ is the lottery prize in the risk preference tasks, and $\gamma /=1$ is the parameter to be estimated. For $\gamma=1$, assume $\mathrm{U}(\mathrm{x})=\ln (\mathrm{w}+\mathrm{x})$ if needed. Thus, $\gamma$ is the coefficient of CRRA: $\gamma=0$ corresponds to being risk neutral, $\gamma<0$ to being risk loving, and $\gamma>0$ to being risk averse. Let there be $\mathrm{k}$ possible outcomes (e.g., $\mathrm{k}=4$ ) in the lottery. Under EUT the probabilities for each outcome $\mathrm{k}, \mathrm{p}_{\mathrm{k}}$, are those induced by the experimenter, so the expected utility is simply the probability-weighted utility of each outcome in each lottery $i$,

$$
E U_{i}=\sum_{k=1, \ldots, 4}\left(p_{k}+U_{k}\right)
$$

The expected utility for each lottery pair is calculated for a candidate estimate of $\gamma$ and the index

$$
\nabla E U=E U_{R}-E U_{L}
$$

is calculated, where EUL is the "left" lottery and EUR is the "right" lottery in the risk preference tasks. This latent index, based on latent preferences, is then linked to the observed choices using a standard cumulative normal distribution function $\Phi($.$) , as (Note 11)$

$$
\operatorname{prob}\left(\operatorname{lottery}_{R}\right)=\Phi(\nabla \mathrm{EU}) .
$$

An important extension of this core model is to allow for subjects to make errors (e.g., mistakes due to carelessness and inattentiveness). The notion of error here is the probability of choosing a lottery that is not one when the EU of that lottery exceeds the EU of the other lottery. One important error specification, due originally to Fechner and popularized by Hey and Orme (1994), posits the latent index as

$$
\nabla E U=\frac{\left(E U_{R}-E U_{L}\right)}{\mu}
$$

where $\mu$ is a structural "noise parameter" used to allow errors from the perspective of the deterministic EUT model. Thus, the likelihood of the observed responses, conditional on EUT and the CRRA specifications being true, depends on the estimates of $\gamma$ and $\mu$ given the above statistical specifications and observed choices. The conditional log-likelihood would be

$$
\left.\ln L^{R A}(\gamma, \mu, \omega, \chi)=\sum_{i}\left(\left(\ln \phi(\nabla E U) \mid y_{i}=1\right)\right)+\left(\ln \phi(1-(\nabla E U)) \mid y_{i}=0\right)\right),
$$

where $\mathrm{y}_{\mathrm{i}}=1$ (or 0 ) denotes the choice of the option "right" (or "left") lottery in risk preference task $\mathrm{i}$ and $\mathrm{X}$ is a vector of individual characteristics reflecting age, sex, race, and so on.

When eliciting individual discount rates, it is the concavity of the utility function that is important, and under EUT this is synonymous with risk attitudes. Andersen et al. (2008) point out that one cannot infer the level of the individual discount rate without knowing that there exists an identification problem which implies that risk attitudes and discount rates cannot be estimated based on discount rate experiments alone but, instead separate tasks to identify the influence of risk preferences must also be implemented.

Specifically, if one assumes that EUT holds for the choices over risky alternatives and that discounting is exponential, then the subject is indifferent between two income options ML and MR if and only if

$$
U\left(M_{L}\right)=\frac{1}{(1+\delta)^{t}} U\left(M_{R}\right)
$$

where $\mathrm{U}\left(\mathrm{M}_{\mathrm{L}}\right)$ is the utility of the monetary outcome $\mathrm{M}_{\mathrm{L}}$ for immediate delivery, $\delta$ is the discount rate, $\mathrm{t}$ is the horizon for the delivery of the later monetary outcome $\mathrm{M}_{R}$, and the utility function $\mathrm{U}$ is separable and stationary over time.

A similar specification for risk aversion is employed for the discount rate choices. The discounted utility of the "left" option (sooner payments) is given by

$$
P V_{L}=\frac{\left(M_{L}\right)^{1-\gamma}}{1-\gamma}
$$


and the discounted utility of the "right" option (later payments) is given by

$$
P V_{R}=\frac{1}{(1+\delta)^{t}} \frac{\left(M_{R}\right)^{1-\gamma}}{1-\gamma}
$$

An index of the difference between these present values, conditional on $\gamma$ and $\delta$, can then be defined as

$$
\nabla \mathrm{PV}=\frac{\left(P V_{R}-P V_{L}\right)}{v}
$$

where $v$ is a noise parameter for the discount rate choices, just as $\mu$ is for the risk aversion choices.

Thus, the likelihood of the discount rate responses, conditional on EUT, CRRA, and exponential discounting specifications being true, depends on the estimates of $\gamma, \delta, \mu$, and $v$, given the observed choices. The conditional log-likelihood is

$$
\left.\ln L^{D R}(\gamma, \delta, \mu, v, y, \omega, \chi)=\sum_{i}\left(\left(\ln \phi(\nabla P V) \mid y_{i}=1\right)\right)+\left(\ln \phi(1-(\nabla P V)) \mid y_{i}=0\right)\right)
$$

where $y_{i}=1$ (or 0 ) denotes the "right" or "left" choice, respectively, in the discounting rate task $i$.

The joint log-likelihood of the risk aversion and discount rate responses can then be written as

$$
\ln L(\gamma, \delta, \mu, v, y, \omega, \chi)=\ln L^{R A}+\ln L^{D R}
$$

Further, when eliciting individual insurance preferences, both the concavity of the utility function and the discount rates are important. A similar specification is employed. The present value of the "buying" option is given by (Note 12).

$$
P U_{b u y}=\frac{1}{(1+\delta)^{t}} \frac{(\omega-\alpha)^{1-\gamma}}{1-\gamma}
$$

and the present value of the "not buying" option is given by

$$
P U_{n b u y}=\frac{1}{(1+\delta)^{t}}\left[p * \frac{(\omega-D)^{1-\gamma}}{1-\gamma}+(1-p) * \frac{\omega^{1-\gamma}}{1-\gamma}\right]
$$

where $\mathrm{w}$ is the endowment earned from the driving task, $\mathrm{D}$ is the potential loss, $\mathrm{p}$ is the loss probability for each insurance task, and $\alpha$ is the insurance premium.

The index of the difference can then be defined as

$$
\nabla P U=P U_{b u y}-P U_{n b u y}
$$

Following the same logic, one can derive the joint log-likelihood of the risk aversion, discount rates, and insurance purchase responses as

$$
\ln L(\gamma, \delta, \mu, v, y, \omega, \chi)=\ln L^{R A}+\ln L^{D R}+\ln L^{I N S}
$$

with the conditional log-likelihood of the insurance purchase as

$$
\left.\ln L^{I N S}(\gamma, \delta, \mu, v, y, \omega, \chi)=\sum_{i}\left(\left(\ln \phi(\nabla P U) \mid y_{i}=1\right)\right)+\left(\ln \phi(1-(\nabla P U)) \mid y_{i}=0\right)\right)
$$

where $y_{i}=1$ (or 0 ) denotes the choice of "buying" or "not buying", respectively, in the insurance purchase task $i$.

\section{Results}

\subsection{Joint Estimation}

Table I presents the maximum likelihood estimates for joint estimation risk attitudes and discount rates allowing homogeneity. In addition to assuming exponential discounting, this section also considers hyperbolic (Mazur) discounting. A hyperbolic specification (Mazur, 1987) assumes that individuals have discount rates that decline with the horizon they face. The functional form (9) can be replaced by

$$
P V_{R}=\frac{1}{1+\delta * t} \frac{\left(M_{R}\right)^{1-\gamma}}{1-\gamma}
$$

The CRRA parameter $\gamma$ is estimated at 0.356 . The estimate of the discount rate is around 1.284 in the exponential discounting and 0.889 in the hyperbolic discounting. Further, there is evidence of noise in the decision process since the p-values for both $\mu$ and $v$ are statistically significant. 
Table 1. Joint estimates of the EUT model allowing homogeneity

(a) Assuming exponential discounting

\begin{tabular}{lccccc}
\hline Parameter & Estimate & Standard Error & p-Value & $95 \%$ Conf. & Interval \\
\hline$\gamma$ & 0.356 & 0.032 & 0.000 & 0.293 & 0.419 \\
$\delta$ & 1.284 & 0.199 & 0.000 & 0.893 & 1.674 \\
$\mu$ (for RA) & 0.939 & 0.080 & 0.000 & 0.782 & 1.096 \\
$\nu$ (for IDR) & 1.366 & 0.289 & 0.000 & 0.799 & 1.934 \\
\hline
\end{tabular}

(b) Assuming hyperbolic (mazur) discounting

\begin{tabular}{lccccc}
\hline Parameter & Estimate & Standard Error & p-Value & $95 \%$ Conf. & Interval \\
\hline$\gamma$ & 0.353 & 0.032 & 0.000 & 0.290 & 0.416 \\
$\delta$ & 0.889 & 0.101 & 0.000 & 0.691 & 1.088 \\
$\mu$ (for RA) & 0.941 & 0.080 & 0.000 & 0.783 & 1.100 \\
$\nu$ (for IDR) & 1.372 & 0.290 & 0.000 & 0.803 & 1.942 \\
\hline
\end{tabular}

Note. $\gamma$ refers to risk attitude; $\delta$ refers to the discount rate; $\mu$ refers to structural error for risk attitudes (RA); $v$ refers to structural error for individual discount rates (IDR).

It is an easy matter to allow $\gamma$ and $\delta$ to be linear functions of the observable characteristics of individuals. Binary indicators are included for sex, age over 25, and race (Asian, Black, or White) (Note 13). Dummies are also included for those having a problem with smoking or alcohol. Each of the core parameters $\gamma$ and $\delta$ is specified as a linear function of these characteristics and the model is estimated using maximum likelihood. Tables 2 and 4 report joint estimations allowing heterogeneity with exponential and hyperbolic discounting, respectively. Allowing for demographic effects for $\gamma$ and $\delta$ improves the prediction of the model by increasing the aggregate log-likelihood from -2420.1541 to -2341.4523 with the exponential discounting specification and from -2413.9438 to -2331.7474 with the hyperbolic discounting specification. Women and non-smokers are significantly more risk averse in the sample. Whites are more risk averse than Black or Asian subjects. Meanwhile, the marginal effects for individual discount rates are reported in Tables 3 and 5. Individual discount rates are more sensitive to race than to other factors. Whites seem more patient than other races in the discounting tasks.

\subsection{Tests of Hypotheses}

The probit model is applied to investigate the role of risk attitudes and discount rates in accident forgiveness purchases. The tests of the hypotheses are divided into two parts. The first part includes general models and the second part includes conditional models that reflect different levels of risk aversion.

Table 6 presents the results assuming exponential discounting and Table 4 assuming hyperbolic discounting. Model 1 in Table 6(a) includes only the variable $\delta$ and the premium while Model 3 also includes the key variable $\gamma$. For both models, the individual discount rate parameter $\delta$ is an important factor in insurance decision-making and its effect is highly significant $(\mathrm{p}<0.05)$. The negative coefficient confirms our hypothesis that policyholders with lower discount rates (or high discount factors) are more likely to purchase an accident forgiveness policy. Table 7 reports the marginal effects of discount rates evaluated at all levels of risk aversion. The results show that more patient individuals are more likely to purchase accident forgiveness at all levels of risk aversion.

Table 2. Joint estimates of the EUT model allowing heterogeneity: exponential discounting

\begin{tabular}{lccccc}
\hline Parameter & Estimate & Standard Error & p-Value & $95 \%$ Conf. & Interval \\
\hline Age25 $_{\gamma}$ & 0.081 & 0.063 & 0.197 & -0.042 & 0.206 \\
Female $_{\gamma}$ & 0.109 & 0.049 & 0.027 & 0.012 & 0.205 \\
Asian $_{\gamma}$ & 0.187 & 0.083 & 0.025 & 0.023 & 0.351 \\
Black $_{\gamma}$ & 0.245 & 0.074 & 0.001 & 0.098 & 0.391 \\
White $_{\gamma}$ & 0.286 & 0.092 & 0.002 & 0.106 & 0.467 \\
Smoker $_{\gamma}$ & -0.233 & 0.065 & 0.000 & -0.360 & -0.105 \\
AlcoholUse $_{\gamma}$ & -0.079 & 0.064 & 0.219 & -0.205 & 0.047 \\
Cons $_{\gamma}$ & 0.081 & 0.082 & 0.323 & -0.080 & 0.243 \\
Age25 $_{\delta}$ & 0.048 & 0.395 & 0.902 & -0.726 & 0.824 \\
Female $_{\delta}$ & -0.232 & 0.026 & 0.387 & -0.758 & 0.294 \\
\hline
\end{tabular}




\begin{tabular}{llllll}
\hline Asian $_{\delta}$ & -1.447 & 0.447 & 0.001 & -2.323 & -0.571 \\
Black $_{\delta}$ & -0.958 & 0.305 & 0.002 & -1.556 & -0.359 \\
White $_{\delta}$ & -1.961 & 0.512 & 0.000 & -2.965 & -0.958 \\
Smoker $_{\delta}$ & 0.214 & 0.243 & 0.378 & -0.262 & 0.692 \\
AlcoholUse $_{\delta}$ & 0.245 & 0.330 & 0.457 & -0.401 & 0.892 \\
Cons $\delta^{\mu \text { (for RA) }}$ & 1.439 & 0.367 & 0.000 & 0.719 & 2.159 \\
\hline (for IDR) & 0.832 & 0.073 & 0.000 & 0.688 & 0.975 \\
\hline
\end{tabular}

Note. $\gamma$ refers to risk attitude; $\delta$ refers to the discount rate; $\mu$ refers to structural error for risk attitudes (RA); $v$ refers to structural error for individual discount rates (IDR).

Table 3. Marginal effects: exponential discounting

\begin{tabular}{lccccc}
\hline Parameter & Estimate & Standard Error & p-Value & 95\% Conf. & Interval \\
\hline Age25 $_{\delta}$ & 0.211 & 1.745 & 0.904 & -3.209 & 3.631 \\
Female $_{\delta}$ & -0.873 & 1.140 & 0.444 & -3.109 & 1.361 \\
Asian $_{\delta}$ & -3.227 & 1.542 & 0.036 & -6.250 & -0.203 \\
Black $_{\delta}$ & -2.601 & 1.368 & 0.057 & -5.282 & 0.080 \\
White $_{\delta}$ & -3.626 & 1.524 & 0.017 & -6.614 & -0.637 \\
Smoker $_{\delta}$ & 1.011 & 1.417 & 0.476 & -1.766 & 3.789 \\
AlcohoUse $_{\delta}$ & 1.174 & 1.838 & 0.523 & -2.428 & 4.777 \\
\hline
\end{tabular}

Note. Marginal effects are measured at the means of the independent variables; $\delta$ refers to the discount rate.

Table 4. Joint estimates of the EUT model allowing heterogeneity: hyperbolic (mazur) discounting

\begin{tabular}{lccccc}
\hline Parameter & Estimate & Standard Error & p-Value & 95\% Conf. & Interval \\
\hline Age25 $_{\gamma}$ & 0.088 & 0.064 & 0.169 & -0.037 & 0.215 \\
Female $_{\gamma}$ & 0.117 & 0.050 & 0.020 & 0.018 & 0.217 \\
Asian $_{\gamma}$ & 0.208 & 0.080 & 0.010 & 0.050 & 0.366 \\
Black $_{\gamma}$ & 0.264 & 0.079 & 0.001 & 0.109 & 0.419 \\
White $_{\gamma}$ & 0.313 & 0.089 & 0.000 & 0.138 & 0.487 \\
Smoker $_{\gamma}$ & -0.238 & 0.065 & 0.000 & -0.367 & -0.109 \\
AlcoholUse $_{\gamma}$ & -0.095 & 0.067 & 0.158 & -0.228 & 0.037 \\
Cons $_{\gamma}$ & 0.057 & 0.082 & 0.484 & -0.103 & 0.219 \\
Age25 $_{\delta}$ & -0.008 & 0.273 & 0.975 & -0.545 & 0.527 \\
Female $_{\delta}$ & -0.171 & 0.175 & 0.328 & -0.516 & 0.172 \\
Asian $_{\delta}$ & -0.971 & 0.267 & 0.000 & -1.496 & -0.446 \\
Black $_{\delta}$ & -0.597 & 0.159 & 0.000 & -0.910 & -0.284 \\
White $_{\delta}$ & -1.404 & 0.360 & 0.000 & -2.111 & -0.697 \\
Smoker $_{\delta}$ & 0.131 & 0.160 & 0.411 & -0.182 & 0.445 \\
AlcoholUse $_{\delta}$ & 0.210 & 0.204 & 0.302 & -0.189 & 0.610 \\
Cons $\delta_{\mu \text { (for RA) }}$ & 0.647 & 0.184 & 0.000 & 0.286 & 1.008 \\
\hline (for IDR) & 0.834 & 0.072 & 0.000 & 0.693 & 0.976 \\
\hline
\end{tabular}

Note. $\gamma$ refers to risk attitude; $\delta$ refers to the discount rate; $\mu$ refers to structural error for risk attitudes (RA); $v$ refers to structural error for individual discount rates (IDR).

Table 5. Marginal effects: hyperbolic (mazur) discounting

\begin{tabular}{lccccc}
\hline Parameter & Estimate & Standard & p-Value & 95\% Conf. & Interval \\
\hline Age25 $_{\delta}$ & -0.016 & 0.518 & 0.975 & -1.033 & 1.001 \\
Female $_{\delta}$ & -0.301 & 0.325 & 0.354 & -0.940 & 0.336 \\
Asian $_{\delta}$ & -1.187 & 0.367 & 0.001 & -1.906 & -0.468 \\
Black $_{\delta}$ & -0.859 & 0.286 & 0.003 & -1.421 & -0.297 \\
White $_{\delta}$ & -1.441 & 0.342 & 0.000 & -2.112 & -0.771 \\
Smoker $_{\delta}$ & 0.269 & 0.364 & 0.460 & -0.444 & 0.983 \\
AlcoholUse $_{\delta}$ & 0.447 & 0.460 & 0.331 & -0.454 & 1.350 \\
\hline
\end{tabular}

Note. Marginal effects are measured at the means of the independent variables; $\delta$ refers to the discount rate. 
Table 6. Insurance purchase probit models, assuming exponential discounting

(a) General Models

\begin{tabular}{cccc}
\hline Variables & Model 1 & Model 2 & Model 3 \\
\hline Discount Rate $(\delta)$ & $-0.253^{* * *}$ & & $-0.386^{* *}$ \\
& $(0.099)$ & & $(0.154)$ \\
Risk Attitude $(\gamma)$ & & 0.379 & -1.131 \\
& & $(0.680)$ & $(1.023)$ \\
Premium & $-0.114^{* * *}$ & $-0.106^{* * *}$ & $-0.118^{* * *}$ \\
& $(0.021)$ & $(0.021)$ & $(0.022)$ \\
Constant & $1.596^{* * *}$ & $1.030^{* * * *}$ & $2.204 * * *$ \\
& $(0.289)$ & $(0.304)$ & $(0.609)$ \\
Observations & 360 & 360 & 360 \\
\hline
\end{tabular}

(b) Conditional Models (based on $\gamma$ below the 25th percentile, 25th to 75th percentiles, and above the 75th percentile)

\begin{tabular}{|c|c|c|c|}
\hline Variables & Model $4(\gamma \leq 0.22)$ & Model $5(0.22 \leq \gamma<0.45)$ & Model $6(\gamma \geq 0.45)$ \\
\hline \multirow[t]{2}{*}{ Discount Rate $(\delta)$} & -0.192 & $-0.913 * * *$ & 1.025 \\
\hline & $(0.163)$ & $(0.342)$ & $(0.935)$ \\
\hline \multirow[t]{2}{*}{ Risk Attitude $(\gamma)$} & 0.156 & -1.938 & $17.794 * * *$ \\
\hline & $(2.055)$ & $(2.395)$ & $(7.170)$ \\
\hline \multirow[t]{2}{*}{ Premium } & $-0.192 * * *$ & $-0.128 * * *$ & $-0.112 * *$ \\
\hline & $(0.039)$ & $(0.030)$ & $(0.055)$ \\
\hline \multirow[t]{2}{*}{ Constant } & $2.361 * * *$ & $3.204 * *$ & $-8.908 * *$ \\
\hline & $(0.850)$ & $(1.270)$ & $(3.848)$ \\
\hline Observations & 90 & 180 & 90 \\
\hline
\end{tabular}

Note. $* * * \mathrm{p}<0.01$, ** $\mathrm{p}<0.05, * \mathrm{p}<0.1$; The 25 th and 75 th percentiles of $\gamma$ are 0.22 and 0.45 , respectively.

Surprisingly, the effect of risk attitudes on insurance purchases exhibits a pattern. Contrary to the prior literature (e.g., Laury \& McInnes, 2003; Kunreuther \& Pauly, 2005), which predicts a positive effect of the degree of risk aversion on insurance purchases, this positive effect is insignificant overall ( $p=0.577$ in Model 2 and $p=0.269$ in Model 3 of Table 6(a)). This implies that, measured at the means, the effect of risk aversion on the demand for insurance is not significant.

However, when the level of risk aversion is controlled, significantly positive effects of risk aversion on insurance purchases are observed. More specifically, three subsamples are defined by centile of risk aversion over all samples. Models 4 to 6 in Table 6(b) include observations with a degree of risk aversion below the 25 th percentile, between the 25 th and 75 th percentiles and above the 75 th percentile, respectively. Note that for less risk averse individuals, risk attitude does not contribute to insurance coverage decisions. On the other hand, the risk preferences of those with a higher degree of risk aversion significantly affect their insurance purchases ( $\mathrm{p}<$ 0.01 in Model 6 of Table 6(b)). This pattern is consistent with the threshold argument, that more risk averse policyholders will be more likely to purchase accident forgiveness if their degree of risk aversion is above a given threshold. Table VIII reports the conditional marginal effects of risk preferences evaluated over different levels of risk aversion and illustrates how the marginal effects of risk aversion $\gamma$ significantly differ, depending on an individual's level of risk aversion. Further, the effects of insurance prices in all models are observed to be significant. This suggests that when premiums are relatively high individuals have less incentive to purchase insurance, which is consistent with previous studies (e.g., Cummins et al., 1974).

Table 7. Conditional marginal effects of time preferences $(\delta)$ evaluated at different risk aversion levels

\begin{tabular}{lcccccc}
\hline$\gamma$ & $\mathrm{dy} / \mathrm{dx}$ & Std. Err. & $\mathrm{z}$ & $\mathrm{P}<|\mathrm{z}|$ & \multicolumn{2}{c}{$95 \%$ Conf. } \\
\hline 0 & -0.103 & 0.025 & -4.05 & 0.000 & -0.153 \\
0.1 & -0.109 & 0.030 & -3.60 & 0.000 & -0.169 \\
0.2 & -0.116 & 0.036 & -3.16 & 0.002 & -0.053 \\
0.3 & -0.121 & 0.042 & -2.86 & 0.004 & -0.187 & -0.204 \\
0.4 & -0.125 & 0.047 & -2.66 & 0.008 & -0.218 \\
0.5 & -0.129 & 0.050 & -2.57 & 0.010 & -0.033 \\
\hline
\end{tabular}


Table 8. Conditional marginal effects of risk preferences $(\gamma)$ evaluated at different risk aversion levels

\begin{tabular}{lcccccc}
\hline$\gamma$ & $\mathrm{dy} / \mathrm{dx}$ & Std. Err. & $\mathrm{z}$ & $\mathrm{P}<|\mathrm{z}|$ & $95 \%$ Conf. & Interval \\
\hline 0 & 0.042 & 0.563 & 0.08 & 0.940 & -1.062 & 1.147 \\
0.05 & 0.042 & 0.559 & 0.08 & 0.940 & -1.054 & 1.139 \\
0.10 & 0.042 & 0.555 & 0.08 & 0.939 & -1.046 & 1.131 \\
0.15 & 0.042 & 0.551 & 0.08 & 0.939 & -1.039 & 1.123 \\
0.20 & 0.041 & 0.547 & 0.08 & 0.939 & -1.031 & 1.115 \\
0.25 & -0.563 & 0.615 & -0.92 & 0.360 & -1.770 & 0.642 \\
0.30 & -0.585 & 0.675 & -0.87 & 0.385 & -1.909 & 0.737 \\
0.35 & -0.605 & 0.724 & -0.83 & 0.404 & -2.025 & 0.815 \\
0.40 & -0.620 & 0.761 & -0.81 & 0.415 & -2.113 & 0.872 \\
0.45 & 4.843 & 1.028 & 4.71 & 0.000 & 2.827 & 6.859 \\
0.46 & 5.314 & 1.313 & 4.05 & 0.000 & 2.740 & 7.888 \\
0.47 & 5.691 & 1.559 & 3.65 & 0.000 & 2.634 & 8.748 \\
0.48 & 5.951 & 1.726 & 3.45 & 0.001 & 2.566 & 9.336 \\
0.49 & 6.077 & 1.789 & 3.40 & 0.001 & 2.569 & 9.585 \\
0.50 & 6.061 & 1.738 & 3.49 & 0.000 & 2.653 & 9.469 \\
\hline
\end{tabular}

Table 9. Insurance purchase probit models, assuming hyperbolic discounting

(a) General Models

\begin{tabular}{lccc}
\hline Variables & Model 1 & Model 2 & Model 3 \\
\hline Discount Rate $(\delta)$ & $-0.721^{* * *}$ & & $-1.194 * * *$ \\
& $(0.272)$ & & $(0.446)$ \\
Risk Attitude $(\gamma)$ & & 0.379 & -1.472 \\
& & $(0.680)$ & $(1.072)$ \\
Premium & $-0.116^{* * *}$ & $-0.106^{* * *}$ & $-0.122^{* * *}$ \\
& $(0.021)$ & $(0.021)$ & $(0.022)$ \\
Constant & $1.899^{* * *}$ & $1.030^{* * *}$ & $2.878^{* * *}$ \\
& $(0.363)$ & $(0.304)$ & $(0.802)$ \\
Observations & 360 & 360 & 360 \\
\hline
\end{tabular}

(b) Conditional Models (based on $\gamma$ below the 25th percentile, 25th to 75th percentiles, and above the 75th percentile)

\begin{tabular}{lccc}
\hline Variables & Model $4(\gamma \leq 0.22)$ & Model $5(0.22 \leq \gamma<0.45)$ & Model 6 $(\gamma \geq 0.45)$ \\
\hline Discount Rate $(\delta)$ & -0.479 & $-1.865^{* *}$ & 1.790 \\
& $(0.466)$ & $(0.777)$ & $(1.382)$ \\
Risk Attitude $(\gamma)$ & 0.399 & -1.687 & $(6.426)$ \\
& $(1.888)$ & $(2.367)$ & $-0.112 * *$ \\
Premium & $-0.187 * * *$ & $-0.129 * * *$ & $(0.055)$ \\
& $(0.038)$ & $(0.032)$ & $-9.282^{* * *}$ \\
Constant & $2.449^{* *}$ & $3.563 * *$ & $(3.451)$ \\
& $(1.006)$ & $(1.467)$ & 90 \\
\hline
\end{tabular}

Note. $* * * \mathrm{p}<0.01, * * \mathrm{p}<0.05, * \mathrm{p}<0.1$; The 25 th and 75 th percentiles of $\gamma$ are 0.22 and 0.45 , respectively.

\section{Reflection}

Learning the best way of conducting an experiment is crucial to obtaining useful and valid results. This section reviews the experimental procedure and comments on what could be improved.

Subjects. The experiment in this paper used students (undergraduates and graduates) from university as subjects. The use of students in studies of consumer behavior is widespread (Enis et al., 1972). Entire classrooms of potential respondents are readily available to academic researchers at little or no cost and these subjects generally follow instructions rapidly and accurately. But these advantages obscure the key question: Do these student responses accurately reflect the behavioral patterns of other consumers (e.g., auto policyholders) in the market? Few would deny that students are consumers, but they are typically psychologically, socially, and 
demographically different from other segments of the population. For example, most subjects in the sample are between 18 and 25 (82\%) and most are therefore covered under their parents' auto policies. A lack of driving or policy purchase experience may affect their choices when making accident forgiveness purchases. That is to say, students' responses to insurance purchase questions may have some variances with those of general policyholders in the market. We believe improvements could certainly be made in this study by recruiting field participants. An efficient way to do this is to collaborate with insurers and use their policyholders as subjects in the insurance policy study. Recruiting real policyholders in the experiment would undoubtedly bring about better insight into insurance policy design.

Driving Behavior. By observing subjects' driving behavior in the simulated driving task, each subject's risk type is determined and used for pricing them in the insurance purchase task. Using a simulated driving task is believed to successfully replicate subjects' driving behavior (e.g., Strayer et al., 2003). However, this approach may have drawbacks. Driving on a simulator requires good hand-to-eye coordination. Although subjects were given one practice drive with the simulator before the paid drive, some subjects may still be uncomfortable with the driving scenarios due to different individual learning curves. Thus, driving behaviors observed from the driving task may be partially explained by relatively poor skills on the simulator rather than true driving skills. In a similar vein, some subjects are "safe" drivers not because they have better driving skills but because they are better at computer racing games. One possible way to solve this problem is to use a driving simulator that enables a subject to drive in a virtual space while operating the controls of an actual vehicle (Note 14) However, this can be very expensive (Note 15). Another way is to provide questionnaires that ask about a subject's driving history (e.g., speeding tickets and at-fault accidents). Inducing subjects to tell the truth about their driving history may improve our understanding of the driving behavior observed in the simulated driving task.

Insurance Contract. In the insurance purchase task, by offering optional insurance to fully cover the potential loss, we imply subjects' preferences for an accident forgiveness policy. However, an accident forgiveness policy in the real market is provided as an optional endorsement attached to the main policy (Note 16). If this is the case, decisions about accident forgiveness policies may be affected by portfolio effects. For example, policyholders who purchase both collision and comprehensive benefits may hesitate to get accident forgiveness because they think they already spent enough money on auto insurance while those who only purchase liability insurance just cannot wait to have it. An ideal solution would be to offer subjects a basic auto policy (e.g., liability, collision and comprehensive policy) first and then ask them to make decisions on accident forgiveness. In such way, we may obtain more information about their decision-making processes.

\section{Conclusions}

While most of experimental literature dwells on controlled laboratory experiments to study insurance purchase decisions, close resemblance to the real insurance market is rare. This study is exploratory because some of the instruments and procedures have not been previously employed for the purpose of generating behavioral data on insurance policy issues in the same way that they are in this study.

In our design, the experiment consists of the following tasks: a lottery choice task, a discount rate task, a simulated driving task, and an insurance purchase task. The lottery choice task and the discount rate task are used to infer risk attitudes and discount rates. Due to the fact that the pricing of accident forgiveness is conditional on the policyholder's driving skills in the market, a simulated driving scenario is used in the driving task to assess the subject's driving behavior. By offering insurance contracts conditional on the observed driving behavior in the insurance purchase task, we construct a close representation of a naturally-occurring auto insurance market in which insurance premiums are based upon driver risk classifications.

Prior literature examining the determinants for individual insurance purchase decisions mostly emphasizes how product quality, switching costs, and price affect consumer decisions (e.g., Schlesinger \& Schulenburg, 1993) or argues that distorted beliefs concerning the probabilities and sizes of potential losses affect consumer decisions about insurance (e.g., Kunreuther \& Pauly, 2004, 2005). Despite this evidence, much is yet to be understood on the roles of risk and time preferences in insurance decision-making. This paper builds on the prior literature on insurance decision-making and theorizes about the role that risk and time preferences play on purchase decisions of accident forgiveness policies. More specifically, two hypotheses are proposed with respect to the effects of individual discount rates and the degree of risk aversion on the accident forgiveness purchase decision: (a) Policyholders with lower discount rates are more likely to have a higher demand for accident forgiveness and (b) more risk-averse policyholders are more likely to purchase accident forgiveness if their degree of risk aversion is above a given threshold.

The findings illustrate that both individual discount rates and insurance price are negatively associated with 
accident forgiveness purchases. Interestingly, the data show that subjects with a relatively low degree of risk aversion behave more like risk-neutral agents when making insurance decisions. In other words, their degree of risk aversion does not con- tribute to their insurance purchases. However, the insurance decisions of those with a higher degree of risk aversion are significantly driven by their risk attitudes. These findings imply that a specific segment of policyholders may be targeted in promoting accident forgiveness policies and that for policyholders whose purchase decisions are less driven by risk attitude, additional incentives (e.g., a good driver discount) may be considered to be bundled with an accident forgiveness policy.

\section{References}

Andersen, S., Harrison, G., Lau, M., \& Rutström, E. (2008). Eliciting Risk and Time Preferences. Econometrica, 76(3), 583-618. https://doi.org/10.1111/j.1468-0262.2008.00848.x

Anderson, R. (1974). The National Flood Insurance Program: Problems and Potential. Journal of Risk and Insurance, 41, 579-599. https://doi.org/10.2307/251956

Camerer, F., \& Ho, T. (1994). Violations of the Betweenness Axiom and Nonlinearity in Probility. Journal of Risk and Uncertainty, 8, 167-196. https://doi.org/10.1007/BF01065371

Camerer, F., \& Hogarth, R. (1999). The Effects of Financial Incentives in Experiments: A Review and Capital-labor-production Framework. Journal of Risk and Uncertainty, 19, 7-42. https://doi.org/10.1023/A:1007850605129

Coller, M., \& Williams, M. (1999). Eliciting Individual Discount Rates. Experimental Economics, 2, 107-127. https://doi.org/10.1023/A:1009986005690

Cox, J., Sadiraj, V., \& Schmidt, U. (2011). Paradoxes and Mechanisms for Choice under Risk. Working Paper 2011-12, Center for the Economic Analysis of Risk, Robinson College of Business, Georgia State University.

Cummins, J. D., McGill, D., Winklevoss, H., \& Zelten, H. (1974). Consumer Attitudes Toward Auto and Homeowners Insurance. Department of Insurance, Wharton School, University of Pennsylvania, Philadelphia.

Dionne, G., \& Doherty, N. (1994). Adverse Selection, Commitment, and Renegotiation: Extension to and Evidence from Insurance Markets. Journal of Political Economy, 102(2), 209-235. https://doi.org/10.1086/261929

Enis, B., Cox, E., \& Stafford, J. (1972). Students as Subjects in Consumer Behavior Experiments. Journal of Marketing Research, 9(1), 72-74. https://doi.org/10.2307/3149612

Fischer, S. (1973). A Life Cycle Model of Life Insurance Purchases. International Economic Review, 14(1), 132-152. https://doi.org/10.2307/2526049

Ganderton, P. T., Brookshire, D., McKee, M., Stewart, S., \& Thurston, H. (2000). Buying Insurance for Disaster-type Risks: Experimental Evidence. Journal of Risk and Uncertainty, 20(3), 271-289. https://doi.org/10.1023/A:1007871514658

Harrison, G. W., Johnson, E., McInnes, M., \& Rutström, E. (2005). Risk Aversion and Incentive Effects: Comment. American Economic Review, 95, 897-901. https://doi.org/10.1257/0002828054201378

Harrison, G. W., Lau, M., \& Williams, M. (2002). Estimating Individual Discount Rates in Denmark: A Field Experiment. The American Economic Review, 92(5), 1606-1617. https://doi.org/10.1257/000282802762024674

Harrsion, G. W., \& Rutström, E. (2008). Risk Aversion in the Laboratory. In J. C. Cox, \& G. W. Harrison (Eds.), Research in experimental economics: 12, Risk aversion in experiments. Bingley: Emerald. https://doi.org/10.1016/S0193-2306(08)00003-3

Harrsion, G. W., \& Rutström, E. (2009). Expected Utility Theory and Prospect Theory: One Wedding and a Decent Funeral. Experimental Economics, 12, 133-158. https://doi.org/10.1007/s10683-008-9203-7

Hey, J. D., \& Lee, J. (2005a). Do Subjects Remember the Past? Applied Economics, 37(1), 9-18. https://doi.org/10.1080/0003684042000286124

Hey, J. D., \& Lee, J. (2005b). Do Subjects Separate (or Are They Sophisticated)? Experimental Economics, 8, 233-265. https://doi.org/10.1007/s10683-005-1465-8

Hey, J. D., \& Orme, C. (1994). Investigating Generalizations of Expected Utility Theory Using Experimental 
Data. Econometrica, 62(6), 1291-1326. https://doi.org/10.2307/2951750

Holt, A., \& Laury, S. (2002). Risk Aversion and Incentive Effects. The American Economy Review, 92(5), 1644-1655. https://doi.org/10.1257/000282802762024700

Krantz, D. H., \& Kunreuther, H. (2007). Goals and Plans in Decision Making. Judgement and Decision Making, 2, 137-168.

Kunreuther, H. (1996). Mitigating Disaster Losses through Insurance. Journal of Risk and Uncertainty, 12, 171-187. https://doi.org/10.1007/BF00055792

Kunreuther, H., \& Pauly, M. (2004). Neglecting disaster: Why dont people insure against large losses? Journal of Risk and Uncertainty, 28(1), 5-21. https://doi.org/10.1023/B:RISK.0000009433.25126.87

Kunreuther, H., \& Pauly, M. (2005). Insurance decision-making and market behavior. Foundations and Trends in Microeconomics, 1, 63-127. https://doi.org/10.1561/0700000002

Kunreuther, H., \& Pauly, M. (2006). Rules Rather Than Discretion: Lessons from Hurricane Katrina. Journal of Risk and Uncertainty, 33, 101-116. https://doi.org/10.1007/s11166-006-0173-x

Kunreuther, H., Novemsky, N., \& Kahneman, D. (2001). Making Low Probabilities Useful. Journal of Risk and Uncertainty, 23, 103-120. https://doi.org/10.1023/A:1011111601406

Laury, S., \& McInnes, M. (2003). The Impact of Insurance Prices on Decision Making Biases: An Experimental Analysis. Journal of Risk and Insurance, 70(2), 219-233. https://doi.org/10.1111/1539-6975.00057

Laury, S., McInnes, M., \& Swarthout, J. (2009). Insurance Decision for Low-probability Losses. Journal of Risk and Uncertainty, 39, 17-44. https://doi.org/10.1007/s11166-009-9072-2

Liu, F. (2015). Accident Forgiveness in the Automobile Insurance Contract. International Journal of Economics and Finance, 7(3), 68-85. https://doi.org/10.5539/ijef.v7n3p68

Mazur, E. (1987). An Adjustment Procedure for Studying Delayed Reinforcement. In M. L. Commons, J. E. Mazur, J. A. Nevin, \& H. Rachlin (Eds.), The Effect of Delay and Intervening Events on Reinforcement Value (pp. 55-76). Hillsdale, NJ: Erlbaum.

McClelland, G. H., Schulze, W., \& Coursey, D. (1993). Insurance for Low-Probability Hazards: A bimodal Response to Unlikely Events. Journal of Risk and Uncertainty, 7, 95-116. https://doi.org/10.1007/BF01065317

Rubinstein, A., \& Yaari, M. (1983). Repeated Insurance Contracts and Moral Hazard. Journal of Economic Theory, 30, 74-97. https://doi.org/10.1016/0022-0531(83)90094-7

Rutström, E. E. (2011). Overview of Experiments on Driving under Uncertain Congestion Conditions with Congestion Pricing Incentives: Hypotheses, Design, Implementation and Analysis. Center for the Economic Analysis of Risk Workshop (December 2011), Georgia State University.

Schlesinger, H., \& Schulenburg, J. (1987). Risk Aversion and the Purchase of Risky Insurance. Journal of Economics, 47(3), 309-314. https://doi.org/10.1007/BF01245150

Schlesinger, H., \& Schulenburg, J. (1993). Consumer Information and Decisions to Switch Insurers. Journal of Risk and Insurance, 60(4), 591-615. https://doi.org/10.2307/253381

Slovic, P., Fischhoff, B., Lichtenstein, S., Corrigan, B., \& Combs, B. (1977). Preference for Insuring Against Probable Small Losses: Insurance Implications. Journal of Risk and Insurance, 44, 237-258. https://doi.org/10.2307/252136

Strayer, D., Drews, F., \& Johnston, W. (2003). Cell Phone-Induced Failures of Visual Attention During Simulated Driving. Journal of Experimental Psychology: Applied, 9(1), 23-32. https://doi.org/10.1037/1076-898X.9.1.23

Warner, J., \& Pleeter, S. (2001). The Personal Discount Rate: Evidence from Military Downsizing Programs. American Economic Review, 91(1), 33-53. https://doi.org/10.1257/aer.91.1.33

Yaari, M. (1965). Uncertain Lifetime, Life Insurance, and the Theory of the Consumer. Review of Economic Studies, 32(2), 137-150. https://doi.org/10.2307/2296058

\section{Notes}

Note 1. A premium increase or surcharge after accidents ranges from $10 \%$ to 50\% (see http://www.dmv.org). 
Note 2. Yaari (1965) considers the subjective discount rate when studying the problem of uncertain lifetimes and life insurance in the context of the expected utility hypothesis using a continuous time model; Fischer (1973) includes a discount factor in the utility-of-consumption function and describes it as a measure of the defectiveness of imagination or impatience.

Note 3. Negative prizes in the lotteries indicate potential loss.

Note 4. PayPal ${ }^{\mathrm{TM}}$ is a private company providing an online payment service. On the payment date, we instructed $\mathrm{PayPal}^{\mathrm{TM}}$ to initiate a transfer for the subject's payment amount to the e-mail address provided. $\mathrm{PayPal}{ }^{\mathrm{TM}}$ then sent the subject an email with a link to its online site where the subject could either register as a user or log in if already member. The money was then immediately available for online purchases or the subject could request that $\mathrm{PayPal}^{\mathrm{TM}}$ send the money in a check with a few days' delay or transfer the money directly to the subject's bank account.

Note 5. The certificate was signed by the director of the Center for the Economic Analysis of Risk at Georgia State University. The payment date, payment amount, and payment methods were clearly specified on the certificate.

Note 6. Subjects were instructed to finish the paid drive within five minutes.

Note 7. For every 10 -second delay, subjects received one penalty point.

Note 8. Subjects who obtained more than five penalty points were paid $\$ 30.00$.

Note 9. Loss from a premium increase after an at-fault accident is relatively low with a relatively high probability compared to loss from other events (e.g., earthquakes). By providing full coverage to the potential loss in the task, we replicate the main feature of the accident forgiveness policy, which is simply full coverage for the loss from the premium increase.

Note 10. Details of this structural estimation approach are reviewed by Harrison and Rutström (2008).

Note 11. A logit specification can also be applied.

Note 12 . To simplify the problem, full coverage is assumed.

Note 13. The base category is a group of other races, including Hispanic-Americans and mixed race.

Note 14. This type of driving simulator is widely used for driver safety education. For example, the Drive Square Simulation System ${ }^{\mathrm{TM}}$ manufactured by Drive Square is the most versatile driving simulator on the market. See http://www.drivesquare.com for details.

Note 15 . Driving simulators range in size and price, from $\$ 20,000$ desktop systems to $\$ 100,000,000$ full-vehicle simulators.

Note 16. An endorsement is a written document attached to an insurance policy that modifies the policy by changing the coverage afforded under the policy.

\section{Copyrights}

Copyright for this article is retained by the author(s), with first publication rights granted to the journal.

This is an open-access article distributed under the terms and conditions of the Creative Commons Attribution license (http://creativecommons.org/licenses/by/4.0/). 